\title{
GAMIFICAÇÃO APLICADA À EDUCAÇÃO: UM RELATO DE EXPERIÊNCIA NA DISCIPLINA HERMENÊUTICA JURÍDICA
}

FORTALEZA/CE MAIO/2018

\author{
Bruna Batista dos Santos - UNIFOR - brunabatista@unifor.br \\ Andrea Chagas Alves de Almeida - UNIFOR - andrea_chagas@unifor.br \\ Ariane Nogueira Cruz - UNIFOR - ariane@unifor.br
}

Tipo: Relato de Experiência Inovadora (EI)

Categoria: Métodos e Tecnologias

Setor Educacional: EDUCAÇÃO SUPERIOR

\begin{abstract}
RESUMO
O processo de ensino-aprendizagem sofre constantes mudanças a cada dia, e incorporar inovações metodológicas, bem como melhorias e sugestões tecnológicas são propostas cada vez mais frequentes, principalmente na modalidade $E a D$. A utilização de novos recursos e técnicas, como a metodologia de gamificação, em materiais educacionais a distância, tem sido uma prática cada vez mais explorada no ensino. Nesse propósito, o presente trabalho constitui-se de um relato de experiência da reestruturação da disciplina de graduação Hermenêutica Jurídica, na modalidade EaD, ofertada pelo Centro de Ciências Jurídicas (CCJ) da Universidade de Fortaleza (UNIFOR). Neste artigo, serão descritos o referencial teórico tais como Gee, Mattar, Móran, dentre outros, que serviu de suporte para a concepção e construção do projeto instrucional da disciplina, a apresentação das metodologias usadas nesse processo de reestruturação, bem como os resultados de tal experiência. Nota-se com isso, que o objetivo de explorar a gamificação na área de ensino, buscando determinar possibilidades e desafios e propor ao aluno uma postura ativa no processo de aprendizagem, contribui para um material mais rico e inovador, além de agregar valor pedagógico ao mesmo.
\end{abstract}

Palavras-chave: Gamificação. Games. Design Instrucional. Experimentação. Hermenêutica Jurídica. 


\section{INTRODUÇÃO}

A educação vem passando por significativas mudanças, tanto na sua forma estrutural como pedagógica e metodológica. No passado o processo de ensino-aprendizagem era voltada para uma relação professor-aluno, realizada de maneira presencial, na qual o papel do estudante era passivo. Com o passar do tempo, pode se observar uma transformação nesse processo que vem tornando o estudante um ator ativo da sua própria formação, apoiado por novas ferramentas e possibilidades metodológicas, além de novas modalidades.

Nessa conjuntura, o Núcleo de Educação a Distância (NEaD) da Universidade de Fortaleza (UNIFOR), o qual existe há aproximadamente 13 anos e oferta disciplinas a distância que fazem parte da grade curricular dos cursos de graduação presenciais, busca implementar nessas disciplinas, a cada semestre, novas possibilidades e recursos aliados a tecnologia. As disciplinas passam constantemente por reformulações, buscando a qualidade e a adequação às inovações tecnológicas e educacionais existentes na âmbito da educação a distância, além de propor em seus conteúdos metodologias, técnicas e estratégias que fazem com que o aluno se torne protagonista no processo de ensino-aprendizagem.

Pensando nesse processo de renovação, no período que compreende de 2017.2 a 2018.1, o NEaD reformulou a disciplina obrigatória do curso de Direito, Hermenêutica Jurídica. A proposta foi modificar uma disciplina totalmente teórica e densa, tornando-a gamificada, com situações práticas e contextualizadas, buscando assim uma aprendizagem mais significativa por parte de seus alunos. Por se tratar de uma disciplina teórica, com pontos históricos e concepções clássicas da área do direito, a missão de gamifica-lá foi um desafio. Desse modo, foram feitas muitas pesquisas e leituras as quais serviram de base para concepção e estruturação do projeto.

\section{OBJETIVOS}

O presente trabalho tem a pretensão de evidenciar a reestruturação da disciplina de Hermenêutica Jurídica do Centro de Ciências Jurídicas (CCJ) da Unifor, na qual buscou criar experiências educacionais significativas, por meio da técnica de gamificação associada à aprendizagem baseada em problemas e outras metodologias ativas de ensino. Por meio desse relato de experiência, apresenta-se propostas inovadoras, que apresentam resultados significativos, tornando o aluno ativo no processo de ensinoaprendizagem, além do estímulo e aplicação do conhecimento teórico, por meio do engajamento e interação professor-aluno e aluno-aluno. 


\section{REFERENCIAL TEÓRICO}

O processo ensino-aprendizagem está mudando. Se antes, ele ocorria apenas dentro da sala de aula, com professor e aluno frente a frente - ou seja, por meio da educação presencial -, hoje, não se pode mais dizer que é somente assim. Atualmente, esse processo pode ser construído, também, por meio da educação a distância (EaD).

A educação a distância se conceitua como a modalidade educacional na qual alunos e professores estão separados, física e/ou temporalmente e, por isso, faz-se necessária a utilização de meios e tecnologias de informação e comunicação para que ocorra a interação aluno-professor. De acordo com o Censo do INEP de 2016, essa modalidade tem crescido vertiginosamente, enquanto o ensino presencial teve queda anual de 0,08\% nas matrículas, o ensino a distância (EAD) teve expansão de 7,2\% (BRASIL, INEP, 2016).

Esse crescimento faz com que as instituições que ofertam cursos livres EaD, pósgraduação e/ou disciplinas $\mathrm{EaD}$ de cursos presenciais prezem pela qualidade e inovação. A qualidade assume posição central diante do impacto das tecnologias e dos novos paradigmas educacionais. O uso de metodologias ativas que proporcionem ao aluno uma postura mais ativa no processo de ensino-aprendizagem também atua como aliada nesse processo.

Tanto na educação presencial quanto na $\mathrm{EaD}$, a utilização de metodologias ativas influenciou, e muito, o jeito de ensinar e aprender. A possibilidade de empregar recursos diferenciados permite mudanças positivas não só na relação entre o discente e docente, mas também no aprendizado do aluno. $E$ isso é reforçado e justificado na modalidade $\mathrm{EaD}$, se entendermos que as metodologias ativas são consideradas inovações pedagógicas, como bem conceitua Mattar no Censo ABED 2016 (2017). Se empregadas de forma pedagogicamente correta, respeitando as especificidades de ensino e os objetivos educacionais, as metodologias ativas possibilitam ao aluno a oportunidade de ter uma postura ativa diante de seu aprendizado.

Com base nessa ideia, Diesel, Baldez e Martins (2017, p. 268) descrevem que "[...] enquanto o método tradicional prioriza a transmissão de informações e tem sua centralidade na figura do docente, no método ativo, os estudantes ocupam o centro das ações educativas e o conhecimento é construído de forma colaborativa". Mattar (2017, p. 21) reforça esse pensando quando aponta que as metodologias ativas podem ser entendidas como "uma educação que pressuponha atividade (ao contrário da passividade) por parte dos alunos". Um dos objetivos nas metodologias ativas, segundo 
Morán (2015) é que o aprendizado se dê a partir de problemas e situações reais, permitindo que os alunos vivenciem de forma antecipada, durante o curso, o que provavelmente só viveriam depois, na vida profissional.

No entanto, fazer com que os alunos tomem essa postura ativa nem sempre é fácil. É necessário que sejam criadas estratégias que despertem o interesse e o engajamento dos aprendizes. A internet e a divulgação de diversos conteúdos, cursos e materiais facilitou bastante o emprego de estratégias inovadoras, mas ainda é complexo e um pouco assustador, visto que não temos modelos prévios bem sucedidos para aprender de forma flexível numa sociedade altamente tradicional. Nesse olhar, Morán, aponta alguns componentes fundamentais para o sucesso da aprendizagem, como por exemplo:

\footnotetext{
a criação de desafios, atividades, jogos que realmente trazem as competências necessárias para cada etapa, que solicitam informações pertinentes, que oferecem recompensas estimulantes, que combinam percursos pessoais com participação significativa em grupos, que se inserem em plataformas adaptativas, que reconhecem cada aluno e ao mesmo tempo aprendem com a interação, tudo isso utilizando as tecnologias adequadas (MORÁN, 2015, $p$. 18).
}

Assim sendo, com o intuito de levar os alunos a ter uma postura mais ativa na construção de seu aprendizado, tornando-o mais significativo, utilizamo-nos da gamificação. Para Deterding et al apud Mattar (2017, p. 85), gamificação é "o uso de elementos de games em contextos que não são de games". De acordo com Navarro, esse termo foi criado pelo programador Nick Pelling, em 2003, e consiste na "aplicação de elementos, mecanismos, dinâmicas e técnicas de jogos no contexto fora do jogo, ou seja, na realidade do dia a dia profissional, escolar e social do indivíduo..." (NAVARRO, 2013, p. 8)

Partindo desse pressuposto, na disciplina, foram empregados alguns elementos de games, como a resolução de missões, pontuação, premiação, dentre outros, com a finalidade de levar os alunos a serem mais participativos, fazendo que que eles aprendam de forma mais prazerosa. Gee (2009, p. 2) diz que "o desafio e a aprendizagem são em grande parte aquilo que torna os videogames motivadores e divertidos." Assim, a proposta para a disciplina era fazer fazer uso das mesmas mecânicas que tornam os games estimulantes, levando o aluno, por meio de desafios, a gostar de aprender.

Pensando nisso, ao projetarmos uma disciplina que se assemelharia a um jogo, na qual os alunos teriam que cumprir missões e tarefas e, posteriormente, receber premiações por isso, estaríamos criando um ambiente ao qual eles se identificassem, permitindo que 
os conhecimentos fossem adquiridos de maneira mais eficaz. Pois como Morán ressalta:

\begin{abstract}
Os jogos e as aulas roteirizadas com a linguagem de jogos cada vez estão mais presentes no cotidiano escolar. Para gerações acostumadas a jogar, a linguagem de desafios, recompensas, de competição e cooperação é atraente e fácil de perceber. Os jogos colaborativos e individuais, de competição e colaboração, de estratégia, com etapas e habilidades bem definidas se tornam cada vez mais presentes nas diversas áreas de conhecimento e níveis de ensino (MORÁN, 2015, p. 18).
\end{abstract}

Neste sentido, este artigo objetiva apresentar a trajetória da reformulação da disciplina de Hermenêutica Jurídica, na modalidade EaD, oferecida pela Universidade de Fortaleza. Tendo como base metodológica a utilização das metodologias ativas e o uso da gamificação.

\title{
4. PROCEDIMENTOS METODOLÓGICOS
}

A disciplina Hermenêutica Jurídica é ofertada, tanto presencialmente quanto a distância, pelo CCJ da Unifor, possui carga horária de 72 horas e faz parte da matriz curricular do curso de Direito, como disciplina obrigatória. A disciplina já é ofertada desde 2008 na modalidade a distância e sempre foi significativamente teórica e densa. No entanto, em meados de 2017 a professora junto com o NEaD propuseram uma mudança metodológica e ajustes no conteúdo para que ficasse mais claro para os alunos o objetivo central da disciplina. Segundo a professora, os estudantes tinham dificuldade de fazer relação entre a teoria e a prática, já que o conteúdo da disciplina valorizava mais os conceitos filosóficos e teóricos em detrimento da prática.

E foi partindo do princípio de estruturar uma disciplina que, além de estimulante e dinâmica, permitisse aos alunos compreender a relevância da hermenêutica jurídica para a prática jurídica, que optamos por fazer a disciplina sob o olhar da inovação, experimentando a metodologia da gamificação.

No primeiro encontro da equipe multidisciplinar, no qual participaram a professoraconteudista, a projetista instrucional, a pedagoga e a coordenadora do NEaD, a professora explicou os principais conceitos referentes ao conteúdo, bem como apresentou os objetivos da disciplina e o plano de ensino, que detalha o número de unidades, a carga horária, os objetivos e outras informações. A partir daí, enquanto a professora-conteudista fazia as devidas adaptações no material, o restante da equipe fez algumas reuniões para socializar as ideias discutidas no primeiro encontro, além de discutir outras questões relevantes ao projeto. Assim sendo, foi pesquisado sobre gamificação, seus elementos, como utilizá-los na disciplina, bem como foram analisados diferentes jogos educacionais. 
Tais pesquisas auxiliaram na criação da estrutura da disciplina, do objetivo de cada fase, dos elementos contidos em cada etapa e das regras para a premiação. Para que o intuito de tornar o processo de ensino-aprendizado mais instigante, dinâmico e eficiente fosse atingido, projetamos a disciplina utilizando algumas mecânicas de jogo, tais como motivação, engajamento, resolução de problemas, pontuação e premiação, criando experiências educacionais significativas e permitindo ao aluno tornar-se personagem ativo nesse processo de ensino-aprendizagem, entendendo a relevância da teoria para a prática.

Assim sendo, como em jogos, nos quais o jogador tem uma missão a cumprir - pegar um objeto, matar mais monstros, conquistar territórios, salvar alguém etc. -, e ele precisa resolvê-la, na disciplina Hermenêutica Jurídica o aluno também recebia uma missão a cada fase e ele tinha que trabalhar para cumpri-la. Ao cumprir a missão, assim como todas as outras tarefas que eram solicitadas, o aluno recebia pontuações e premiações. Entende-se que utilizar a gamificação não era produzir ou utilizar games nos ambientes virtuais de aprendizagem, mas sim a ideia da gamificação foi criar rotas de aprendizagem personalizadas, bem como apresentação para o aluno do seu progresso, missões, uso de conquistas dentre outros elementos.

Sabe-se que os games

[...] delegam aos seus leitores um tipo de liberdade que os leitores de um texto não possuem. O leitor de um game assume simultaneamente a posição de autor, pois contribui para a sua construção. Além de interpretar, o leitor de um game precisa se esforçar para progredir na história (MATTAR, 2017, p. 80).

Seguindo a lógica de tornar o aluno protagonista de seu processo de aprendizagem, a disciplina foi dividida em cinco fases. Em cada fase, o aluno teria que percorrer cinco etapas (cada uma com uma cor diferente) para que ele pudesse atingir o objetivo final: cumprir sua missão. A missão consistia em resolver um caso, uma situação real. Para isso, os alunos tinham que se utilizar dos conhecimentos da hermenêutica jurídica. Desse modo, cada fase ficou dividida da seguinte forma:

- Etapa Caso (amarela) - Nesta etapa, a aluno tinha conhecimento do caso jurídico que ele teria que resolver. Assim, a missão era uma problematização relativa a esse caso e, para tentar resolvê-la, o aluno tinha que ter como base os conteúdos trabalhados na fase. Em cada uma das cinco fases, os respectivos casos foram apresentados de diferentes formas: áudio, imagens, histórias em quadrinhos e vídeo.

- Etapa Argumento (cinza) - Aqui, o aluno tinha acesso à lei relativa ao caso.

- Etapa Conceito (verde) - Nela, o aluno poderia visualizar o material didático - 
texto e vídeo - referente àquela fase. Esse material, juntamente com a lei, forneciam munição para que o aluno pudesse resolver a missão.

- Etapa Desafio (vermelha) - Nessa etapa, o aluno tinha acesso a um desafio em forma de quiz, com questões relativas ao conteúdo trabalhado na respectiva fase.

- Etapa Missão (azul) - Por fim, nesta etapa, o aluno deveria oferecer sua resposta à situação-problema que the fora dada. Lembrando que ele não poderia dar uma resposta qualquer, mas sim, uma solução justificada pelo conteúdo da disciplina.

Um ponto importante a ser elucidado é quanto ao fato da nomenclatura e às expressões utilizadas. Visto que a disciplina foi pensada de modo a se parecer com um jogo, os termos utilizados para denominar os elementos foram semelhantes aos de games. Assim sendo, "unidade" tornou-se "fase", o "aluno" passou a se chamar "participante", os "exercícios" viraram "desafios", existiam as "conquistas" - as quais os alunos iam obtendo ao longo das etapas ao realizarem determinadas tarefas, e as "missões". A comunicação com o aluno era feita de maneira direta e objetiva e eram utilizadas expressões comumente usadas no universo dos games como "boa sorte" ou "sua missão é...".

Assim também como em alguns jogos, foi produzido um Manual do Participante, o qual continha todas as informações que os alunos precisavam saber a respeito da estrutura, das regras e da premiação do "jogo". Também com intuito de motivar os alunos, fazendo-os participativos na resolução das tarefas propostas e da missão, foram atribuídas conquistas, as quais poderiam ser revertidas em pontuação extra para os alunos. Para ganharem essas conquistas, os alunos tinham que cumprir tarefas específicas no ambiente virtual de aprendizagem. São as conquistas:

- Competitor: essa conquista era atribuída a quem cumpriu a primeira tarefa, que era se apresentar aos outros participantes no fórum;

- Lex: essa conquista era atribuída a quem acessava todos os elementos da etapa Argumento;

- Philosophus: para conquistá-la, o aluno precisava acessar todos os elementos da etapa Conceito;

- Ferox: para conseguir essa conquista, a aluno tinha que cumprir o desafio da fase;

- Missio: essa conquista era atribuída a quem cumpriu a missão;

- Peritum: para alcançar essa conquista, o aluno tinha que conseguir todas as outras.

É importante ressaltar que os nomes das conquistas têm relação com a tarefa a qual o 
participante tinha que cumprir. Assim, por exemplo, a conquista denominada Lex palavra latina que significa "lei" - era atribuída aos alunos que visualizaram todos os elementos da etapa Argumento, na qual continha o texto da lei relativa ao caso. Por mais que não foi tenha sido elaborado um game propriamente dito, percebe-se que a utilização da gamificação, também permitiu o aluno se engajar e ser ator nesse processo de aprendizagem, contribuindo para sua construção. Afinal, para que "se consiga a máxima efetividade no processo de aprendizagem, são necessários o engajamento e a participação ativa dos autores envolvidos neste processo ensino-aprendizagem" (SOUZA, 2000, p. 42). Desse modo, os alunos sentiram-se estimulados a assumir a construção do conhecimento, responsabilizando-se por ela.

\section{APRESENTAÇÃO E DISCUSSÃO DOS RESULTADOS}

Apesar da disciplina, nessa nova estrutura, ter sido reestruturada em 2017.2 e ofertada no semestre de 2018.1 como experimentação, acredita-se que já tem experiências exitosas. Na construção desse projeto foi alcançado alguns resultados, entre eles lidar com o desafio de envolver a professora no processo de construção de todo conteúdo da disciplina que iria ministrar, tirando-a da zona de conforto e do olhar tradicional do ensino-aprendizagem, envolvendo-a na metodologia da gamificação, como a própria metodologia diferenciada, que foi inovador e exigiu da equipe multidisciplinar muito estudo e engajamento para fazer sentido e ser ofertado.

Em relação à professora, a maior dificuldade enfrentada nos primeiros contatos com ela, foi convencê-la e demonstrar que os objetos de aprendizagem tradicionais utilizados até então, não ajudavam no envolvimento do aluno, tornando participante ativo do processo, deixando-o passivo nessa relação e permitindo alguns pré-conceitos diante da modalidade EaD. No entanto, a resistência foi realmente minimizada nos primeiros encontros presenciais uma vez que este contato foi se tornando de fácil comunicação entre professora e aluno tanto pelo ambiente virtual, como fora dele.

Já com relação a utilização de recursos digitais associados a metodologia ativa de gamificação permitiu que novas práticas ampliassem antigas possibilidades, potencializou-se a reestruturação das práticas pedagógicas, e o engajamento e envolvimento dos alunos foi notado de maneira naturalmente intensa.

Como já dito anteriormente, o objetivo de utilizamos elementos de gamificação no projeto instrucional da disciplina Hermenêutica Jurídica era proporcionar aos alunos, através da prática, uma experiência dinâmica e prazerosa, que os levasse a refletir e perceber a relevância dos conhecimentos adquiridos para suas vidas enquanto futuros 
juristas. Nesse sentido, a disciplina elaborada pelo NEaD espera cumprir uma função pedagógica de desenvolver uma aprendizagem pautada na relação teórico-prática, que permita ao aluno desenvolver competências necessárias para sua prática profissional. Agregar metodologias ativas em um curso EaD revelou um grande potencial na proposta da disciplina de Hermenêutica Jurídica na modalidade a distância, pois a partir da discussão em torno das soluções de problemas passou a gerar aprendizagem compartilhada, despertando o interesse no aluno pelos temas propostos e assim favorecendo sua aprendizagem significativa.

\section{CONSIDERAÇÕES FINAIS}

Incluir elementos de jogos no processo de ensino-aprendizagem é, indubitavelmente, expandir as possibilidades de experiências que podem ser vivenciadas pelos alunos. Quando falamos em práticas andragógicas, é imprescindível que saibamos que o ensino apenas por transmissão - aquele no qual o professor tem o papel de, apenas, repassar os conteúdos para os alunos -, em geral, não é a maneira mais adequada para formar adultos, uma vez que esses valorizam mais a experiência e a prática. A experiência de desenvolver uma disciplina na qual utilizássemos mecânicas de jogos para beneficiar a aprendizagem dos alunos permitiu à equipe aprofundar seus conhecimentos a respeito de jogos e gamificação, enriquecendo ainda mais a formação dos profissionais do NEaD.

\section{REFERÊNCIAS BIBLIOGRÁFICAS}

BRASIL. Ministério da Educação - INEP - Instituto Nacional de Estudos e Pesquisas Educacionais. Anísio Teixeira. Ministério da Educação. Censo da Educação Superior 2016: Notas estatísticas. Brasília, 2016. Disponível em: Acesso em: 30 abr. 2018.

\section{Censo EAD.BR: Relatório Analítico da Aprendizagem a Distância no Brasil $2016=$} Censo EAD.BR: Analytic Report of Distance Learning in Brazil/. [traduzido por Maria Thereza Moss de Abreu]. Curitiba: InterSaberes, 2017. Disponível em: Acesso em: 30 abr. 2018.

DIESEL, Aline; BALDEZ, Alda Leila Santos; MARTINS, Silvana Neumann. Os princípios das metodologias ativas de ensino: uma abordagem teórica. Thema, Instituto Federal de Educação, Ciências e Tecnologia Sul-rio-grandense. Pelotas, RS, Brasil, V.14, n. 1, p. 268-288, 2017. Disponível em: Acesso em: 01 maio 2018.

GEE, James Paul. Bons videogames e boa aprendizagem. Perspectiva, Florianópolis, 
v. 27 , n. 1, p. 167-178, jan. 2009. ISSN 2175-795X. Disponível em: . Acesso em: 30 abr 2018.

MATTAR, João. Metodologias ativas: para educação presencial, blended e a distância. 1 ed. São Paulo: Artesanato Educacional, 2017.

MORÁN, José. Mudando a educação com metodologias ativas. In: SOUZA, Carlos Alberto de; MORALES, Ofelia Elisa Torres (orgs.). Coleção Mídias Contemporâneas. Convergências Midiáticas, Educação e Cidadania: aproximações jovens. Vol. II. PG: Foca Foto-PROEX/UEPG, 2015. Disponível em: . Acesso em: 01 maio 2017.

NAVARRO, Gabrielle. Gamificação: a transformação do conceito do termo jogo no contexto da pós-modernidade. 2013. Disponível em: Acesso em: 27 abr. 2018.

SOUZA, Renato Rocha. Aprendizagem colaborativa em comunidades virtuais. Dissertação, Mestrado em Engenharia de Produção - Curso de Pós-Graduação em Engenharia de Produção, Universidade Federal de Santa Catarina, Florianópolis, 2000. Disponível em: Acesso em: 01 maio 2018. 